\title{
Time Window
}

\section{Dear Reader,}

Actually, the IAA offered enough forward-looking topics to underline the innovative power of the automotive industry. But after "Dieselgate” at Volkswagen, nothing remains - unfortunately! Instead, public perception is dominated by a scandal which consequences will cast a shadow not only over Volkswagen, but rather over an entire industry.

Because it has been known for years that the official fuel consumption and emissions indications deviate from the realworld values and that actual $\mathrm{NO}_{\mathrm{x}}$ emissions from vehicles are many times higher in real operation than on test benches. The continuing high levels of $\mathrm{NO}_{2}$ in German cities resulting from these emissions are nothing new either. Nevertheless, all parties have been haggling for years over new testing procedures, exceptions and the right time to introduce them - as if they were at a cattle market. Instead, it should be about the kind of world we want to leave to our children.

What is important now is, at long last, to introduce a worldwide harmonised test cycle (WLTC) with new test procedures (WLTP) quickly, sustainably and effectively to take account of Real Driving Emissions (RDE). However, what is even more important is that the automotive industry uses the narrow time window that is now available before the European and national political decisionmakers set their own parameters, and that it goes on the offensive in addressing the subject of clean diesel technology. Only in this way will it be able to show how $\mathrm{NO}_{\mathrm{x}}$ emissions can be reduced by using innovative technology and document that it is taking the issue of RDE seriously. ATZ and MTZ would be happy to deal extensively with this issue, applying the full range of knowledge available. Until now, this has all too often failed due to a lack of willingness in the industry to make information available. But it is now time to do this, thus underlining the innovative power and responsibility of the companies involved.

Electric mobility is now unstoppable, and especially after this scandal it is likely to develop more rapidly than previously forecast. The $48-\mathrm{V}$ theme will find its way, both top-down and bottomup, into future vehicle models - in particular as a vehicle electrical system for hybrid vehicles. But these also require an internal combustion engine. If we want to prevent this engine, and especially the diesel, from being written off as "dirty" in the coming decades of transition to the age of electrification, immediate and proactive measures are necessary.

The aim is therefore to use this time window effectively and powerfully. ATZ and MTZ will focus even more strongly on this area, and we are looking forward to the topics raised by the industry.

Best regards,

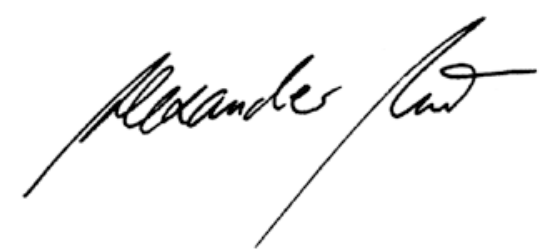

Dr. Alexander Heintzel Editor in Chief

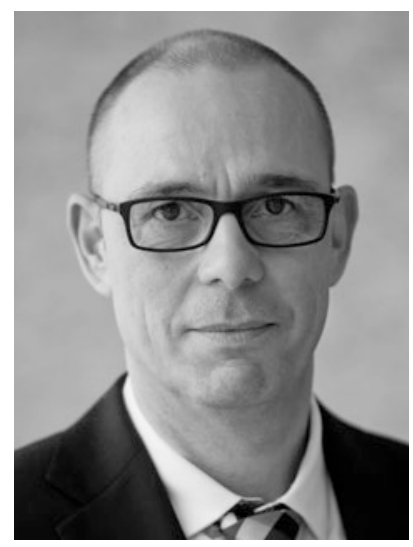

